\title{
Foraging behavior analysis of swarm robotics system
}

\author{
E. Sakthivelmurugan ${ }^{1 *}$, G. Senthilkumar ${ }^{1}$, K. G. Prithiviraj ${ }^{1}$ and K. R. Tinu Devraj ${ }^{1}$ \\ ${ }^{1}$ Department of Mechanical Engineering, Bannari Amman Institute of Technology, Sathyamangalam, \\ Erode, Tamilnadu, India.
}

\begin{abstract}
Swarm robotics is a number of small robots that are synchronically works together to accomplish a given task. Swarm robotics faces many problems in performing a given task. The problems are pattern formation, aggregation, Chain formation, self-assembly, coordinated movement, hole avoidance, foraging and self-deployment. Foraging is most essential part in swarm robotics. Foraging is the task to discover the item and get back into the shell. The researchers conducted foraging experiments with random-movement of robots and they have end up with unique solutions. Most of the researchers have conducted experiments using the circular arena. The shell is placed at the centre of the arena and environment boundary is well known. In this study, an attempt is made to different strategic movements like straight line approach, parallel line approach, divider approach, expanding square approach, and parallel sweep approach. All these approaches are to be simulated by using player/stage open-source simulation software based on $\mathrm{C}$ and $\mathrm{C}++$ programming language in Linux operating system. Finally statistical comparison will be done with task completion time of all these strategies using ANOVA to identify the significant searching strategy.
\end{abstract}

Keywords: Foraging, Swarm Robotics, Foraging Algorithm, Item Searching Strategy, Item Detection Time.

\section{Introduction}

In current environment more people are subjected into hazardous work such as toxic waste clean-up, demining, search and rescue. In such a work the reliability of human life is relatively too low. In order to overcome that issue, the people are replaced with group of small robots. The group of small robots will accomplish the task at very faster and efficient manner. For this task accomplishment, various foraging behaviour is considered [1].

Many researchers have studied the behaviour of swarm robotics system. Also they have focused on these characteristics of swarm robotics system and applied the system to concrete problems from the engineering viewpoint. But most of them resort to study the qualitative aspect of swarm robotic system. And also they have studied swarm robotics by

\footnotetext{
*Corresponding author: sakthi.glen@gmail.com
} 
adopting the swarm intelligence to mimic a swarm by lot of robots. In daily life social insects play some intelligent activities[3]. Also the researchers have concentrated only on random movements of robots with circular arena. The shell is placed in the centre of the circular arena. But they have not concentrated on various strategic movements of robots such as expanding square approach, expanding square with divider policy, parallel sweep approach and parallel sweep with divider policy. In this study, various strategic movements of robots and item inclusions are planned to be studied.

The objective of this study is to reduce the time consumption for searching through various strategic movements of robots with different strategies. And also to find the resource utilization, task completion time and efficiency of the system. This study will helpful to search the item in faster mode compare to random search. There is no possibility of collision and congestion in searching state and retrieving state. It will improve the system efficiency because of better utilization of resources. There is no interaction needed between robots because robots are placed at well defined arena.

\section{Methodology}

It explains about the various possible movements of robots from one stage to another stage through robot activity diagram. Also it explains about various assumptions to be followed in the foraging behaviour and various item searching techniques.

\subsection{Robot Activity Diagram}

In this swarm robotic system, various kinds of strategic movements are considered for the purpose of retrieving item to the shell. The possible robot activity was described in figure 1 .

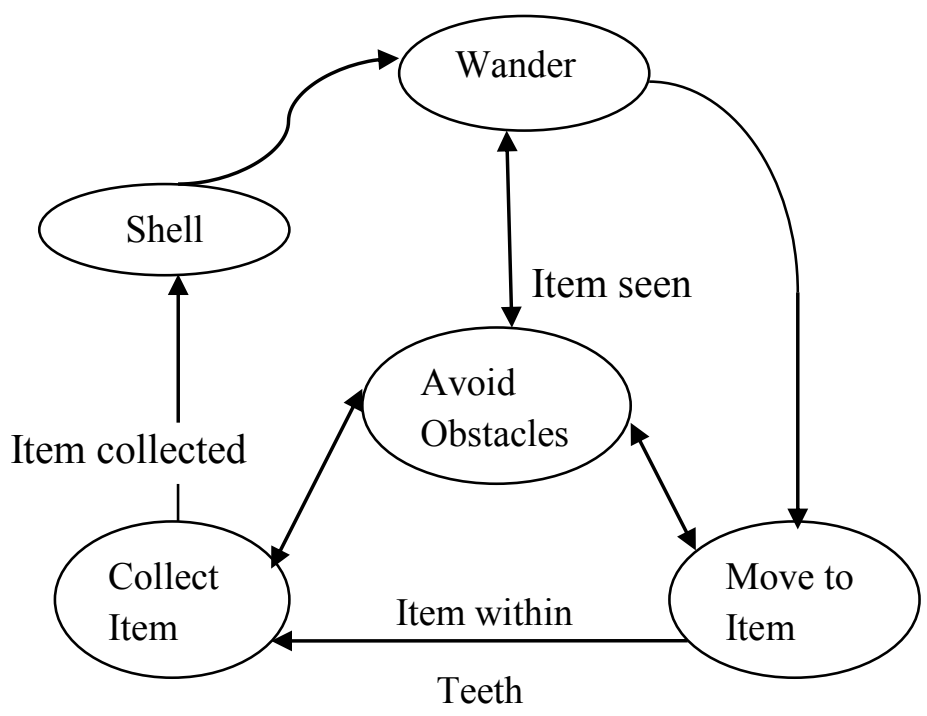

Fig. 1. Robot Activity Diagram 


\subsection{Assumptions}

1. Limited number of robots is used.

2. Item is considered as a stationary object.

3. Environment boundary is well known.

4. Congestion and collisions are neglected.

5. Obstacles inclusion also considered.

6. Position of shell is well known.

\subsection{Foraging Algorithm}

Step 1: Start the program.

Step 2: Enable the port address.

Step 3: Calling the robots by the address R1, R2, R3, R4.

Step 4: Initialize variables Count $=0$, Delay time $=2$ Sec, Total number of item $N=20$, Bitmaps.

Step 5: Robots R1, R2, R3, R4 wandering.

Step 6: If any one of the robots R1, R2, R3, and R4 detects the item, it goes to step 7 . Otherwise, it goes to step 5.

Step 7: Robot move to the item.

Step 8: If any other robots contact with the item means it enters into the ignore state. After delay of $2 \mathrm{Sec}$ it goes to step 5. Otherwise, it goes to step 9.

Step 9: Robot makes physical connection with the item.

Step 10: Robot move to the shell.

Step 11: Robot release the item in the shell.

Step 12: If total count less than the total number of item means it goes to step 5 . Otherwise it goes to step13.

Step 13: Print the total task completion time for a given arena.

Step 14: Stop the program.

\subsection{Various Item Searching Strategies}

Different types of item searching strategies are given below. 
1. Straight line approach

2. Divider approach

3. Parallel sweep approach

4. Expanding square approach

5. Parallel line approach

\subsubsection{Straight Line Approach}

In this approach, the arena is divided into four sub elements. The shell is placed at bottom of the each sub elements boundary line. Also item is positioned throughout the environment. In this environment obstacles also placed. This environment is to be simulated and also total task completion time has to record.

\subsubsection{Divider Approach}

In this approach, the arena is divided into four sub elements. Here the shell is placed at each sub elements left corner side. The robot will search the item at allocated area only and do not interrupt with others. At last this environment is to be simulated and also total task completion time has to record.

\subsubsection{Parallel Sweep Approach}

In this approach, the arena is sweep in nature. Here, the shell is placed at bottom or top of the boundary line. Alternate search is possible in this approach. Finally this environment is to be simulated and also total task completion time has to record.

\subsubsection{Expanding Square Approach}

In this approach, the arena like square in nature. But square expands from one end to another end. Here also the shell is placed at either side of boundary line. Item and obstacles are placed throughout the environment. At end this environment is to be simulated and also total task completion time has to record.

\subsubsection{Parallel Line Approach}

This is similar to the straight line approach. In this case the arena is subdivided into eight elements. The shell is placed at top and bottom of the boundary line. Here the number of robots is high. This will applicable only, if the environment large in nature.

\section{Simulation setup}

For simulation Arena size, Number of robots, Strategy and Arena was described in table 1. 
Table 1. Simulation Setup

\begin{tabular}{|c|l|c|c|c|c|}
\hline S. No. & Type of Strategy & $\begin{array}{l}\text { No. of } \\
\text { Robots }\end{array}$ & Area (m $\left.\mathbf{m}^{\mathbf{2}}\right)$ & Width (m) & Length (m) \\
\hline 1 & $\begin{array}{l}\text { Parallel sweep } \\
\text { with divider }\end{array}$ & 4 & $2.4 \times 3$ & 2.4 & 3.0 \\
\hline 2 & $\begin{array}{l}\text { Parallel sweep } \\
\text { with divider }\end{array}$ & 4 & $3 \times 3.5$ & 3.0 & 3.5 \\
\hline 3 & $\begin{array}{l}\text { Parallel sweep } \\
\text { without divider }\end{array}$ & 4 & $2.4 \times 3$ & 2.4 & 3.0 \\
\hline 4 & $\begin{array}{l}\text { Parallel sweep } \\
\text { without divider }\end{array}$ & 4 & $3 \times 3.5$ & 3.0 & 3.5 \\
\hline
\end{tabular}

\subsection{Factorial design and strategy comparison}

\subsubsection{Introduction}

When the number of factor increases, the number of experimental runs would be very large. Especially in the screening experiments conducted to develop new processes or new products, the number of factors considered will usually be large since the experimenter has no prior knowledge on the problem. Because resources are usually limited, the experimenter may restrict the number of replications. When only one replication is obtained, we will not have the experimental error for testing the effects.

\subsection{Factor identification}

In item searching mode a lot of factors that affects the robot performance. Here a strategy only plays a major role or any other factors are significantly contributed towards this robot performance. For this performance analysis, we considered the following factors namely Speed, Size of Arena, Number of Robots and Type of Strategy.

\subsubsection{Factors Level Selection}

Each factor was tested at two levels (low level and high level). The maximum allowable speed for the robot in the simulation is $1.0 \mathrm{~m} / \mathrm{sec}$. beyond that speed limit robot may collide with other robots or congestion will be possible. But the size of the arena, type of strategy and number of robots will be any according to their experimenter interest. Factors level is given in the table 2. In mentioned table, factors and levels are simulated by using player/ stage simulation software and responses are tabulated. With help of Yates algorithm, sum of squares and estimate of effect is calculated and tabulated in table 3. 
Table 2. Various levels for each factor

\begin{tabular}{|c|l|c|c|}
\hline S. No. & \multicolumn{1}{|c|}{ Factors } & Low Level & High level \\
\hline 1 & Speed of the Robot (A) & $0.5(\mathrm{~m} / \mathrm{sec})$ & $1.0(\mathrm{~m} / \mathrm{sec})$ \\
\hline 2 & Size of the Arena (B) & $20 \times 30\left(\mathrm{~m}^{2}\right)$ & $50 \times 30\left(\mathrm{~m}^{2}\right)$ \\
\hline 3 & Number of Robots (C) & 2 & 4 \\
\hline 4 & Type of Strategy (D) & 1 & 2 \\
\hline
\end{tabular}

Table 3. Yates Algorithm for the $2^{4}$ Design (Single Replicate)

\begin{tabular}{|c|c|c|c|c|c|c|c|c|c|}
\hline $\begin{array}{l}\text { S. } \\
\text { No. }\end{array}$ & $\begin{array}{c}\text { Treatmen } \\
\mathbf{t} \\
\text { combinati } \\
\text { on } \\
\text { (s) }\end{array}$ & $\begin{array}{c}\begin{array}{c}\text { Resp } \\
\text { onse } \\
\text { (Tim } \\
\text { e) }\end{array} \\
\end{array}$ & (1) & (2) & (3) & (4) & Effect & $\begin{array}{l}\text { Estimate } \\
\text { of Effect }\end{array}$ & $\begin{array}{c}\text { Sum of } \\
\text { squares }\end{array}$ \\
\hline 1 & (1) & 105 & 232 & 802 & 1295 & 2617 & I & & \\
\hline 2 & A & 127 & 570 & 493 & 1322 & -881 & $\bar{A}$ & -110.13 & 48510.0 \\
\hline 3 & B & 449 & 159 & 862 & -459 & 1023 & B & 127.88 & 65408.0 \\
\hline 4 & $\mathrm{ab}$ & 121 & 334 & 460 & -422 & -591 & $\mathrm{AB}$ & -73.88 & 21830.0 \\
\hline 5 & $\mathrm{C}$ & 102 & 264 & -306 & 513 & -711 & $\mathrm{C}$ & -88.88 & 31595.0 \\
\hline 6 & $\mathrm{ac}$ & 54 & 598 & -153 & 510 & 379 & $\mathrm{AC}$ & 47.38 & 8977.56 \\
\hline 7 & $\mathrm{bc}$ & 218 & 142 & -324 & -401 & -321 & $\mathrm{BC}$ & -40.13 & 6440.06 \\
\hline 8 & $a b c$ & 116 & 318 & -98 & -190 & 429 & $\mathrm{ABC}$ & 53.63 & 11502.5 \\
\hline 9 & $\mathrm{D}$ & 173 & 22 & 338 & -309 & 27 & $\mathrm{D}$ & 3.38 & 45.56 \\
\hline 10 & $\mathrm{ad}$ & 91 & -328 & 175 & -402 & 37 & $\mathrm{AD}$ & 4.63 & 85.56 \\
\hline 11 & bd & 420 & -51 & 334 & 153 & -3 & $\mathrm{BD}$ & -0.38 & 0.56 \\
\hline 12 & abd & 178 & -102 & 176 & 226 & 211 & ABD & 26.38 & 2782.56 \\
\hline 13 & $\mathrm{~cd}$ & 88 & -82 & -350 & -163 & -93 & $\mathrm{CD}$ & -11.63 & 540.56 \\
\hline 14 & acd & 58 & -242 & -51 & -158 & 73 & ACD & 9.13 & 333.06 \\
\hline 15 & bcd & 191 & -34 & -160 & 299 & 5 & $\mathrm{BCD}$ & 0.625 & 1.56 \\
\hline 16 & abcd & 127 & -64 & -30 & 130 & -169 & $\mathrm{ABCD}$ & -21.13 & 1785.06 \\
\hline
\end{tabular}

With help of analysis of variance, Degrees of freedom and percentage contribution of source of variation is computed and tabulated in table 4. From this table, we observed that source of variations such as $\mathrm{A}, \mathrm{B}, \mathrm{C}$ and $\mathrm{AB}$ are significantly contributed. The remaining source of variation is not significantly contributed and that is combined with error for conducting the $\mathrm{F}$ - Test. The $\mathrm{F}$ - Test is conducted and tabulated in table 5 . 
Table 4. Analysis of Variance for $2^{4}$ design

\begin{tabular}{|c|c|c|c|}
\hline Source of Variation & Sum of Squares & $\begin{array}{c}\text { Degrees of } \\
\text { Freedom }\end{array}$ & Contribution (\%) \\
\hline $\mathrm{A}$ & 48510.06 & 1 & 24.27 \\
\hline $\mathrm{B}$ & 65408.06 & 1 & 32.73 \\
\hline $\mathrm{AB}$ & 21830.06 & 1 & 10.92 \\
\hline $\mathrm{C}$ & 31595.06 & 1 & 15.81 \\
\hline $\mathrm{AC}$ & 8977.56 & 1 & 4.49 \\
\hline $\mathrm{BC}$ & 6440.06 & 1 & 3.22 \\
\hline $\mathrm{ABC}$ & 11502.56 & 1 & 5.76 \\
\hline $\mathrm{D}$ & 45.56 & 1 & 0.02 \\
\hline $\mathrm{AD}$ & 85.56 & 1 & 0.04 \\
\hline $\mathrm{BD}$ & 0.56 & 1 & 0.003 \\
\hline $\mathrm{ABD}$ & 2782.56 & 1 & 1.40 \\
\hline $\mathrm{CD}$ & 540.56 & 1 & 0.27 \\
\hline $\mathrm{ACD}$ & 333.06 & 1 & 0.17 \\
\hline $\mathrm{BCD}$ & 1.56 & 1 & 0.008 \\
\hline $\mathrm{ABCD}$ & 1785.06 & 1 & 0.89 \\
\hline $\mathrm{T}$ otal & 199837.9 & 15 & 100 \\
\hline
\end{tabular}

Table 5. Analysis of Variance after Pooling

\begin{tabular}{|c|c|c|c|c|}
\hline Source of Variation & Sum of Squares & $\begin{array}{c}\text { Degrees of } \\
\text { Freedom }\end{array}$ & Mean Square & F $_{\mathbf{0}}$ \\
\hline $\mathrm{A}$ & 48510.06 & 1 & 48510.06 & $16.42(\mathrm{~S})$ \\
\hline $\mathrm{B}$ & 65408.06 & 1 & 65408.06 & $22.14(\mathrm{~S})$ \\
\hline $\mathrm{AB}$ & 21830.06 & 1 & 21830.06 & $7.39(\mathrm{~S})$ \\
\hline $\mathrm{C}$ & 31595.06 & 1 & 31595.06 & $10.70(\mathrm{~S})$ \\
\hline Pooled error & 32494.66 & 11 & 2954.06 & \\
\hline
\end{tabular}

Table 6. Normal probability computations of the effects

\begin{tabular}{|c|c|c|c|}
\hline Effect & Rank & Percentile & Rank-based z-score \\
\hline-110.13 & 1 & 0.0333333 & -1.833914636 \\
\hline-88.88 & 2 & 0.1 & -1.281551566 \\
\hline-73.88 & 3 & 0.1666667 & -0.967421566 \\
\hline-40.13 & 4 & 0.2333333 & -0.727913291 \\
\hline-21.13 & 5 & 0.3 & -0.524400513 \\
\hline-11.63 & 6 & 0.3666667 & -0.340694827 \\
\hline-0.38 & 7 & 0.4333333 & -0.167894005 \\
\hline 0.63 & 8 & 0.5 & $-1.39214 \mathrm{E}-16$ \\
\hline
\end{tabular}




\begin{tabular}{|c|c|c|c|}
\hline 3.38 & 9 & 0.5666667 & 0.167894005 \\
\hline 4.63 & 10 & 0.6333333 & 0.340694827 \\
\hline 9.13 & 11 & 0.7 & 0.524400513 \\
\hline 26.38 & 12 & 0.7666667 & 0.727913291 \\
\hline 47.38 & 13 & 0.8333333 & 0.967421566 \\
\hline 53.63 & 14 & 0.9 & 1.281551566 \\
\hline 127.88 & 15 & 0.9666667 & 1.833914636 \\
\hline
\end{tabular}

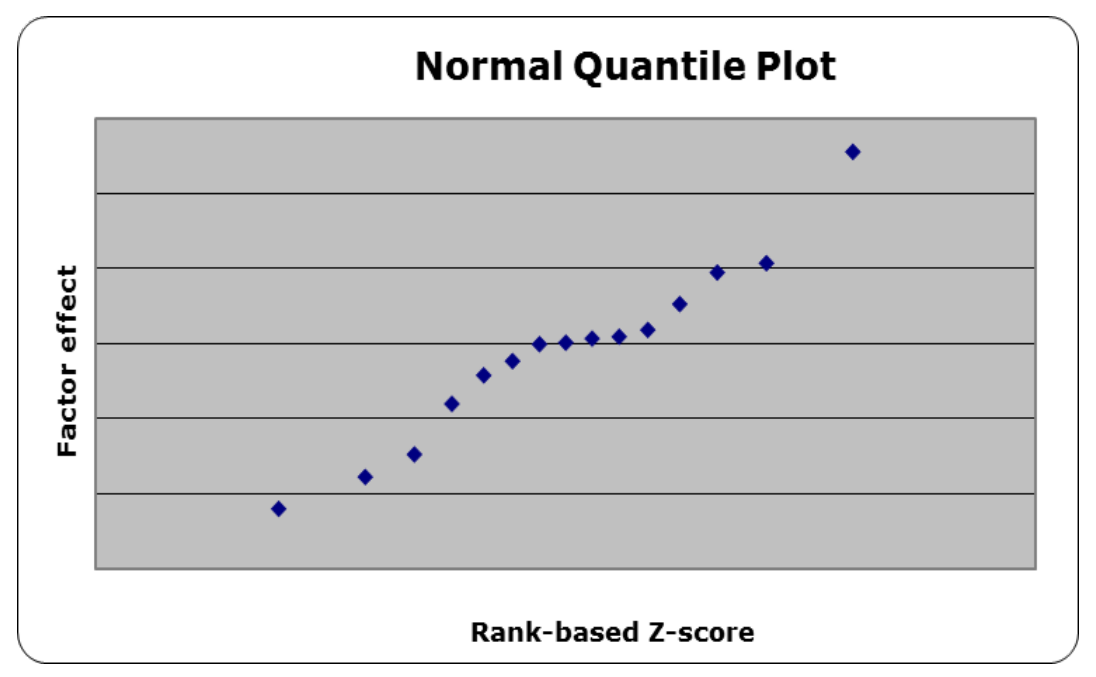

Fig. 2. Normal probability plot of factor effects for single replication

At $5 \%$ level of significance $\left(\mathrm{F}_{1,11}=4.84\right), 2.5 \%$ level of significance $\left(\mathrm{F}_{1,11}=6.72\right)$, main factors $\mathrm{A}, \mathrm{B}, \mathrm{C}$ and two factor interactions $\mathrm{AB}$ are significant as revealed by the normal probability plot.

\subsection{Inference from factor identification}

From this analysis, we noticed that in item searching mode apart from the strategies there are several factors plays a major role. But speed level, size of the arena and number of robots most significantly contributed towards this item searching mode. In order to avoid the collision and congestions, the experimenter must consider these three parameters for designing the experiment.

\subsection{Various strategies item detection time comparison}

It is very essential part in the simulation. Strategy that gives minimum item detection time based on the speed level, number of robots and size of the arena that should be the best strategy. For various strategies item detection time comparison is given in table 7 . 
Table 7. Various Strategies Item Detection Time Comparison

\begin{tabular}{|l|l|l|l|l|l|l|l|}
\hline & \multirow{2}{*}{$\begin{array}{l}\text { S. } \\
\text { No. }\end{array}$} & \multirow{2}{*}{$\mathbf{( m} / \mathbf{s e c})$} & \multirow{2}{*}{$\begin{array}{l}\text { Size of the } \\
\text { Arena }\left(\mathbf{m}^{2}\right)\end{array}$} & \multirow{2}{*}{$\begin{array}{l}\text { No of } \\
\text { Robots }\end{array}$} & & \multicolumn{5}{|c|}{ Item Detection Time (Sec) } \\
\cline { 5 - 9 } & & & & $\mathbf{1}$ & $\mathbf{2}$ & $\mathbf{3}$ & $\mathbf{4}$ \\
\hline 1 & 0.5 & $20 \times 30$ & 2 & 105 & 173 & 204 & 158 \\
\hline 2 & 0.5 & $50 \times 30$ & 4 & 218 & 191 & 208 & 198 \\
\hline 3 & 1 & $20 \times 30$ & 2 & 127 & 91 & 152 & 124 \\
\hline 4 & 1 & $50 \times 30$ & 4 & 116 & 127 & 132 & 122 \\
\hline 5 & 0.5 & $20 \times 30$ & 4 & 105 & 88 & 120 & 102 \\
\hline 6 & 1 & $20 \times 30$ & 4 & 54 & 52 & 68 & 60 \\
\hline 7 & 0.5 & $50 \times 30$ & 2 & 449 & 424 & 428 & 430 \\
\hline 8 & 1 & $50 \times 30$ & 2 & 121 & 178 & 142 & 164 \\
\hline
\end{tabular}

\subsubsection{Inference from Various Strategies Item Detection Time Comparison}

From this various strategies Item detection time comparison, we noticed that the second strategy parallel sweep with divider policy gives minimum item detection time with various combinations of speed level, size of the arena and number of robots. According to the eight combinations of these three parameters Parallel sweep with divider policy contributed more compared with other three strategies. So finally, we concluded that parallel sweep with divider policy be the best strategy along with other three strategies

\section{Conclusions}

Swarm robotics is a number of small robots that are synchronically works together to accomplish a given task. It can be applied to many fields such as agriculture field, mining field, manufacturing industries and military purposes. Foraging is most essential part in swarm robotics. Foraging can be applied to a wide range of useful tasks such as toxic waste cleanup, search and rescue, demining, collection of terrain samples, deep sea and Polar Regions. The foraging behavior of multi-robot system is studied through the various literatures. From literatures various types of algorithms, mathematical model and computer simulations characteristics was studied. For this project state transition diagram, logical flow chart, algorithm, various types of item searching strategy and octagonal robot was developed. Various item searching strategies such as expanding square approach, expanding square with divider policy, parallel sweep approach and parallel sweep with divider policy are simulated by using player/stage software. From the Statistical analysis parallel sweep with divider policy be the best strategy along with other three strategies. 


\section{Scope for future work}

- This paper mainly focused on foraging behaviour of swarm robotics system. Apart from foraging behaviour, there are many problem present in swarm robotics system such as pattern formation, aggregation, hole avoidance, self deployment and chain formation. It is possible to simulate all swarm robotics problem using player/ stage simulation software.

- In this work, few item searching strategies are developed and simulated. In future, the researcher can develop new strategies and it is possible to simulate with different simulation package.

- In this work, number of robots, arena size and position of item and shell are predefined. In future, the researcher can increase number of robots, arena size according to development of new strategies.

\section{References}

1. L. Bayindir and E. Sahin (2007) "A Review of Studies in Swarm Robotics", The Turkish Journal of Electrical Engineering and Computer Science Vol.15, No.2, pp. 115-147.

2. Campo and M. Dorigo, V. Longchamp, S. Garnier and C. Pinciroli (2010) "Artificial pheromone for path selection by a foraging swarm of robots", The Journal of Biological Cybernectics vol.103, pp. 339-352

3. Campo and M. Dorigo (2007) "Efficient Multi-foraging in Swarm Robotics", Book Advances in Artificial Life, 9th European Conference, ECAL, vol.4648, pp. 696-705, Lisbon, Portugal.

4. R. Hoff, A. Sagoff, J. Wood and R. Nagpal (2010) "Two Foraging Algorithms for Robot Swarms Using Only Local Communication”, International Conference on Robotics and Biomimetics (ROBIO), pp. 123-130, Tianjin.

5. J. Lee, H. Kim and C. Ahn (2012) "Foraging Swarm Robots System Adopting Honey Bee Swarm for Improving Energy Efficiency", International Conference on Ubiquitous Information Management and Communication, ICUIMC '12, Kulalumpur, Malasia.

6. D. Lambrinos, R. Moller, R. Labhart, R. Pfeifer and R. Wehner (2000) "A mobile robot employing insect strategies for navigation", The Journal of robotics and autonomous systems, pp 39-64.

7. K. Sugawara, M. Sano, I. Yoshihara, K. Abe and T. Watanabe (1999) "Foraging Behavior of Multi-robot system and Emergence of Swarm Intelligence", International Conference on System, Man and Cybernetics, Vol.3,pp.257-262,Tokyo.

8. R. Sharpe and B. Webb (1998) "Simulated and situated models of chemical trail following in ants", International conference on simulation of adaptive behaviour, $\mathrm{pp}$ $195-204$.

9. K. Krishnaiah and P. Shahabudeen, "Applied Design of Experiments and Taguchi Methods", The Book ISBN-978-81-203-4527-0, pp. 85-153. 